\title{
Blue rubber bleb nevus syndrome: endoscopic treatment with sclerotherapy during double-balloon enteroscopy in a 9-year-old boy
}

Blue rubber bleb nevus syndrome (BRBNS), also called Bean syndrome, is a rare disease associated with multiple venous malformations essentially in the skin and the gastrointestinal (GI) tract $[1,2]$. It commonly presents with anemia and patients respond to supportive measures, but severe symptoms may be treated by surgical resection, endoscopic sclerotherapy, and laser photocoagulation $[3,4]$.

We report here a case of BRBNS presenting with $\mathrm{Gl}$ bleeding in a 9-year-old boy who was first diagnosed at the age of 1 , with a venous angioma in the knee. The onset of melena led to a complete exploration of the upper and lower GI tract, and capsule endoscopy, which revealed several typical blue lesions in the stom-

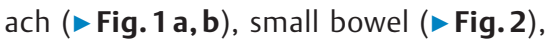
and colon ( $\triangleright$ Fig. $1 \mathrm{c}$ ).

Gastric and colonic lesions were first treated with argon plasma coagulation ( Fig.3) in the pediatric hospital. The patient was then referred to our unit for double-balloon enteroscopy (EN-580T; Fujifilm, Tokyo, Japan), through which we could identify five pedunculated lesions and four flat friable ones. The progression of the endoscope was difficult owing to the small size of the intestinal loops; however, successful sclerotherapy of the lesions was achieved by injecting aetoxisclerol ( $\triangleright$ Video 1$)$. Apart from these angiomas, no further lesions required treatment, according to capsule endoscopy. The patient did not experience any new bleeding after this treatment.

In conclusion, BRBNS is rare but the diagnosis has to be considerd when typical lesions are seen in different areas. Double-balloon enteroscopy using an adult enteroscope appears to be feasible in children, but progression is probably more difficult in a small-diameter bowel. As previously demonstrated, aetoxisclerol seems to be effective for the treatment of lesions with low risk of perforation.

Endoscopy_UCTN_Code_TTT_1AP_2AD

Competing interests

\section{None}

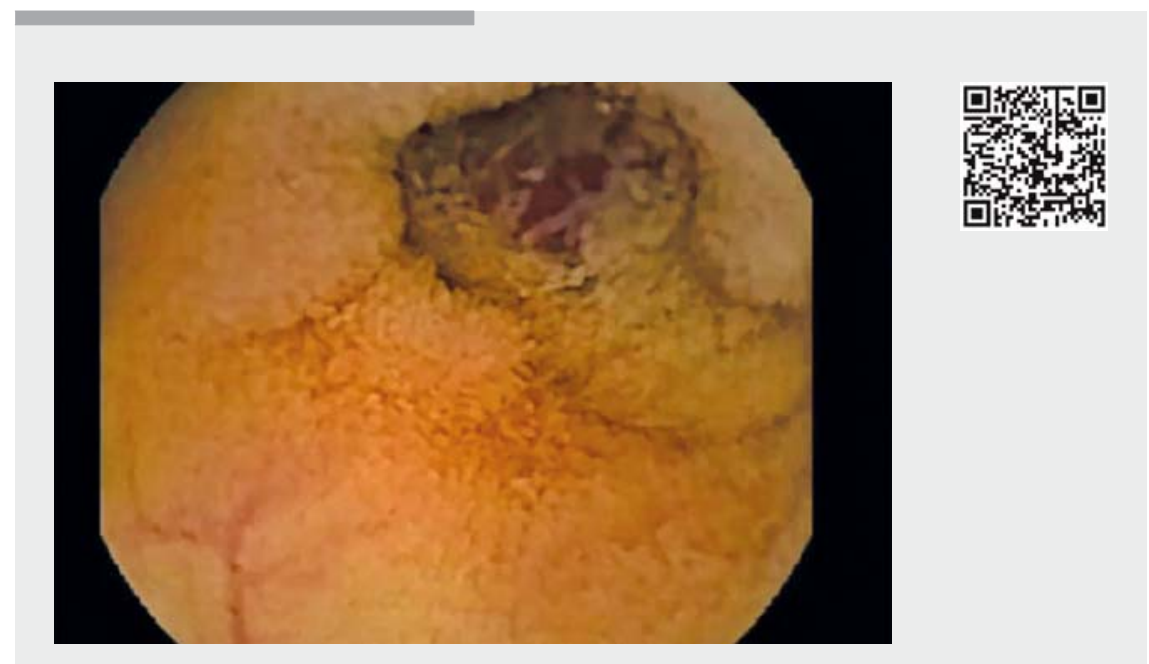

$\checkmark$ Video 1 Video capsule endoscopy diagnosis and double-balloon endoscopic sclerotherapy of gastrointestinal angiomas.
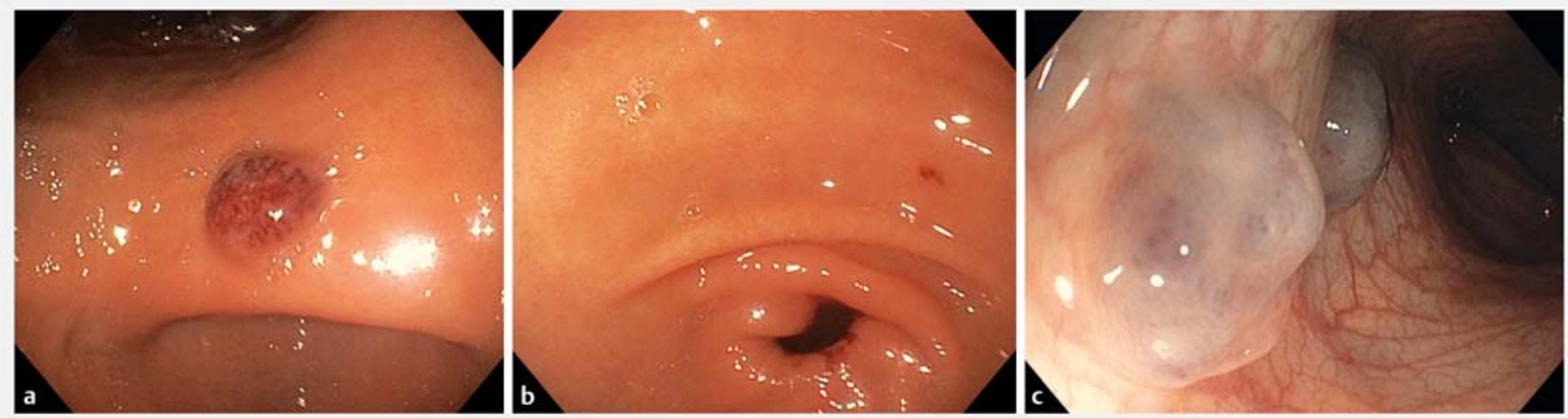

- Fig. 1 Endoscopic view of the angiomas. a Gastric antral lesion. b Gastric pre-pyloric lesion. c Colonic lesion. 

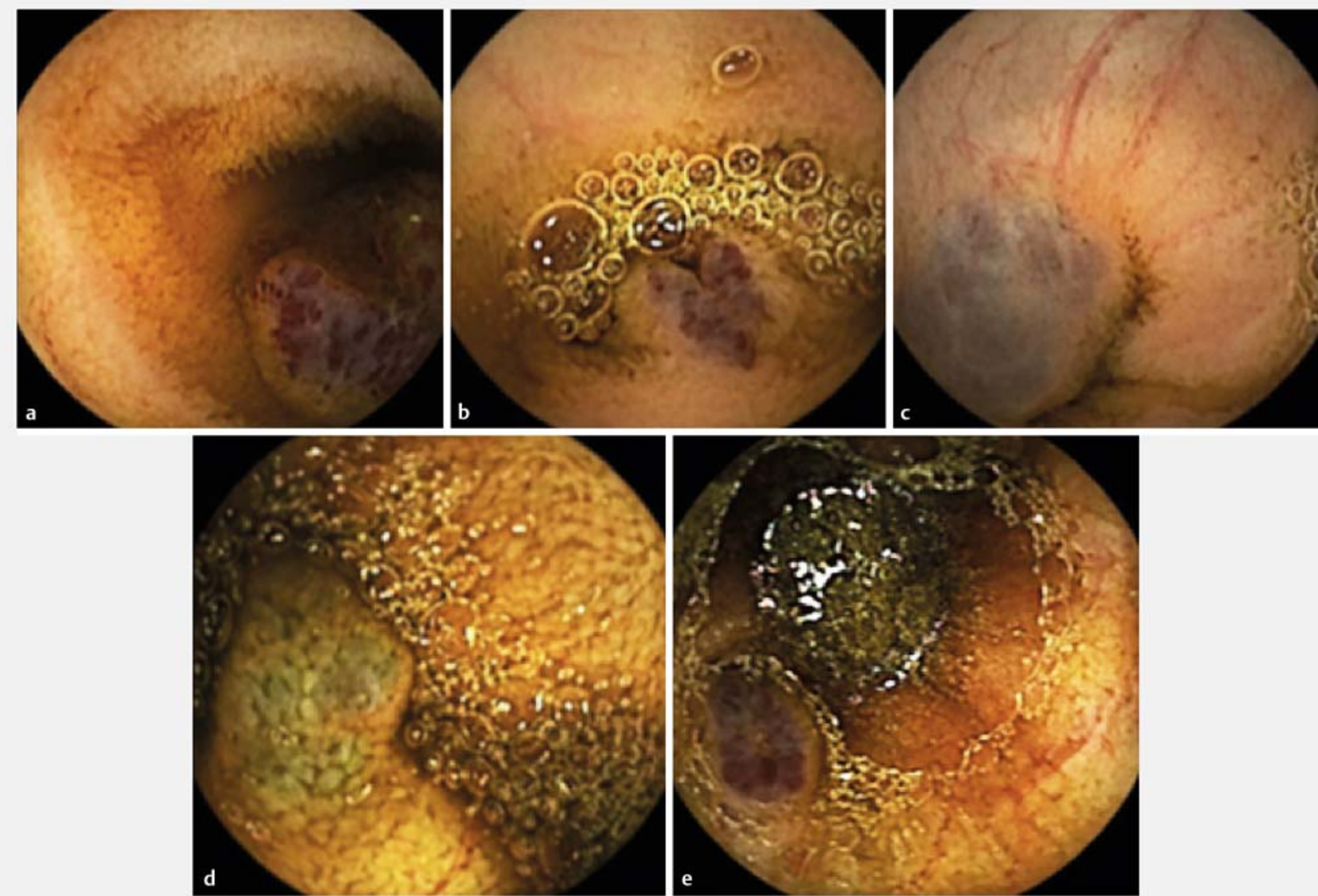

Fig. 2 Capsule endoscopic views of angiomas in the small bowel.
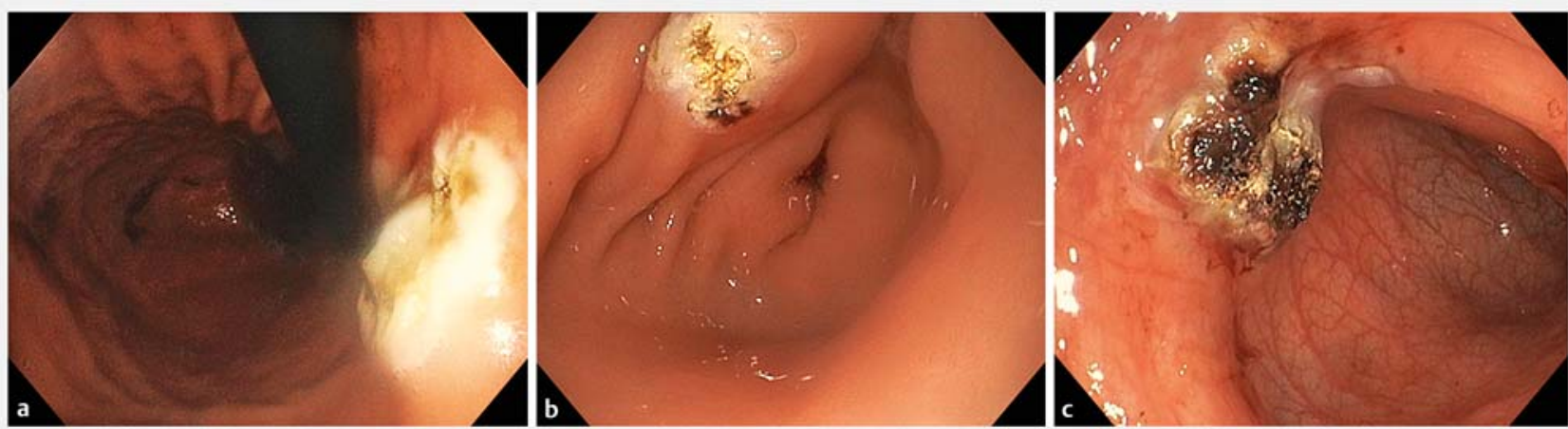

- Fig. 3 The lesions after treatment with argon plasma coagulation. a Gastric antral lesion. b Gastric pre-pyloric lesion. c Colonic lesion. 
The authors

Maria Carolina Malafaia ${ }^{1}$, Sophie Heissat ${ }^{2}$, Philippe Jacob ${ }^{2}$, Catherine Le Gall², Mathias Ruiz $^{2}$, Jean-Christophe Saurin ${ }^{3}$, Mathieu Pioche ${ }^{3,4}$

1 Department of General and Digestive Surgery, Professor Alberto Antunes University Hospital, Maceió, Alagoas, Brazil

2 Department of pediatric gastroenterology, Hospital Femme Mere Enfant, Lyon

3 Department of Endoscopy and Gastroenterology, Pavillon L, Edouard Herriot Hospital, Lyon, France

4 Inserm U1032 LabTau, Lyon, France

Corresponding author

\section{Mathieu Pioche, MD}

Endoscopy Unit - Digestive Disease Department, Pavillon L - Edouard Herriot Hospital, 69437 Lyon Cedex, France Fax: +33-4-72110147

mathieu.pioche@chu-lyon.fr

\section{References}

[1] El Bakkaly A, Ettayebi F, Oubeja $\mathrm{H}$ et al. Bean's syndrome in children: about two cases. Article in French. Pan Afr Med J 2017; 28: 102

[2] Arena M, Virdis M, Morandi E et al. Blue rubber bleb nevus syndrome: combined surgical and endoscopic treatment. Endoscopy 2015; 47 (Suppl. 01): E372 -E373

[3] Jin XL, Wang ZH, Xiao XB et al. Blue rubber bleb nevus syndrome: a case report and literature review. World J Gastroenterol 2014 20: $17254-17259$

[4] Tang X, Gao J, Yang X et al. A 10-year delayed diagnosis of blue rubber bleb nevus syndrome characterized by refractory irondeficiency anemia: a case report and literature review. Medicine (Baltimore) 2018; 97 e10873

Bibliography

DOI https://doi.org/10.1055/a-0840-3214

Published online: 12.2.2019

Endoscopy 2019; 51: E98-E100

(c) Georg Thieme Verlag KG

Stuttgart · New York

ISSN 0013-726X
ENDOSCOPY E-VIDEOS

https://eref.thieme.de/e-videos

回局 Endoscopy E-Videos is a free access online section, reporting 17f: on interesting cases and new techniques in gastroenterological endoscopy. All papers include a high quality video and all contributions are freely accessible online.

This section has its own submission website at https://mc.manuscriptcentral.com/e-videos 